\title{
Negotiating Intimacies in an Eroticized Environment: Xiaojies and South China Entertainment Business
}

\author{
Yu Ding \\ Sun Yat-sen University
}

This paper draws on the experience of a group of xiaojies (female sex workers) in the Pearl River Delta region (PRD), South China, to discuss how marriage and intimate relations exert a long-term ongoing influence on these women's rural-urban migrations and work choices, and how the highly developed sex industry in the coastal region poses difficulties, as well as creates opportunities, for them to rethink what they want in their intimate relations. Without legal identity, or economic, social and cultural capital, and bearing prostitute stigma, they can only accumulate resources from the most mundane and trivial acts - yet these yield life improvement only in a superficial way. Nevertheless, this boosts their self esteem and brings positive emotions. The sex business is a "special" kind of business that is based on mutual monetary (material) exchange, and yet involves a lot more than that. It is a nexus where morality, emotion, gender relations, social, cultural and economic redistribution, human rights, legislation, regional development, etc., are interwoven to influence the experiences of the people involved, and the whole social milieu that sustains it. This paper also shows some of the special features of the sex industry, using cases in the PRD as examples.

\section{PROLOGUE}

I miss him... But I hate him too!! Why has he brought so much trouble to me and why do I need to suffer so much for him? I want to forget about him. I am in pain... (Hong, 2005)

Hong writes this in her diary when her boyfriend is detained for drug addiction. "Love", "miss", "hate", "pain" - these words are everywhere in her diary, as well as in her conversations. She loves her boyfriend, but also hates him for his total dependence on her. She became addicted to heroin after getting to know this addicted boyfriend. She solicits on streets to support their everyday expenditures, including those for drugs. She does not think this man can bring her the sense of security she wants because he is a drug addict and has no regular income, but she feels deeply in love and believes that he has a special affection for her. She wants to remain single and avoid the complicated emotions involved in being intimate with a man who is dependent on her in every way, including financially - but she also longs for a good family life. She does not think 
of herself as formally working, since what she does is only "to earn enough money for him and me to have a meal and a dose". Almost every aspect of her life is related to this man, whom she does not want to acknowledge as her boyfriend, although he turns out to be the one that she loves, lives for, and emotionally depends on.

\section{INTRODUCTION}

Sex business is a business form that has existed almost as long as human beings. Today it refers to "commercial goods and services of an erotic and sexual kind" (Agustin, 2005: 618) - e.g. pornography, sex tourism, sex shops, brothels, adult entertainment, escort, hotel services, and many other forms. It is multi-dimensional and ever evolving. Although monetary or material exchange is its basic rationale, like other kinds of business, the "product" it provides is nonetheless very different from that in other kinds of businesses. It is hard to define, and thus provokes controversy and ongoing academic debates. Sociologists, anthropologists, and feminists, as well as practitioners and advocates, have discussed what is being "sold and bought" during sex transactions - is it sex? Body? Sexual skills? Emotion? Labor? Or prostitutes' power or rights? These discussions lead to further questions. For instance, can sex be separated from one's body? Can sexual labor be sold and exchanged? Do the women involved have the power to decide and control during the transactions? Is prostitution a mutual exchange based on free will or is it oppression? Different schools of thought hold different viewpoints, from seeing prostitution as patriarchal coercion and the women involved as passive victims, as does radical feminism (Pateman, 1988; Barry, 1995), to viewing it as a matter of ordinary business contracts and normal work relations, as does liberal feminism (Califia, 1994; Chapkis, 1997).

Sex business exists and proliferates in different parts of the world, and diverse socialcultural-economic conditions in different regions render it a complex issue that needs contexualization and cultural sensitivity. Research on it is interdisciplinary, as it brings together discussions about morality, emotion, gender relations; social, cultural and economic development; human rights, legislation, regional development, public health, sex ratio balance, etc. It thus requires integrated and compound ways to view and analyze it. The body of studies that see prostitution from both the business and cultural/anthropological perspective is still limited. As Agustin points out, the rich and wide milieu that makes up the sex industry - e.g., in the Chinese context, culture, family, marriage, consumption, emotion, intimacy, urban/rural divide, sexuality, migration, citizenship rights, gender relations, and so on - is neglected, and so a large number of ways to study it are excluded (Agustin, 2005). However, perspectives and methods of business anthropology provide a fresh input to our discussions of this issue. A focus on work processes, group behavior, consumer behavior, organizational change, globalization/diversity (Jordan, 2010), and cultural and ethical issues (Chapman, 1996; Jordan, 2010) may give us insights into how the sex business gradually forms and develops, how local social/economic/cultural development contributes to its proliferation and diversification, how it operates in a certain region, how people involved experience, negotiate, resist or integrate, etc. Only when we situate ourselves in a wider context can we have a better understanding of individual life in a certain environment.

This paper attempts cultural sensitivity and full contextualization. It draws upon the experience of a group of xiaojies and their clients and intimate partners in both their work places and everyday life in three South China metropolises: Guangzhou, Shenzhen, and Dongguan. In this paper I use the word "xiaojie" instead of "female sex worker" to refer to prostitute women. 
Xiaojie, literarily "little sister", was a respectful way to refer to and address young unmarried women in China, but it has lately become a common term for "prostitute woman". It is a term of address preferred by the prostitute women themselves, unlike the term "sex worker".

Most of these women come from small towns or rural parts of China. They are part of the grand rural-urban migration that has taken place since the opening-up of China. Stories like Hong's are not uncommon among the women that I interviewed. My fieldwork shows that marriage and love are important issues for the xiaojies. Our conversations would often slip into the topic of love and relations, no matter what we were talking about. Most of the women would mention their husbands, boyfriends or ex-boyfriends in the interviews and conversations, although they may have brought them more pain than happiness. I found that, behind their happy or unhappy stories, they were often able to come to decisions concerning love life and intimacy, and to justify them. From the data I realized that love and intimate relations are important to explore if I want to understand these xiaojies' lives.

This paper aims to answer 1) how xiaojies' love lives influence their life paths and choices; 2) what they want concerning intimate relations; and 3) how they challenge marriage as an institution through various sexual and erotic practices. I examine how the women's desire to be more open, autonomous, sexual, young, urban, etc.; and their sense of security, self esteem and self love; interplay to exert on-going influences in many aspects of their lives, including their migrations, experiences in the sex business, future aspirations, etc. Their migration experiences and ideals of love and intimacy are mutually constituted - i.e. their love or marriage experiences are some of the most powerful driving forces of their rural-to-urban migrations. On the other hand, migration itself has profoundly influenced their views and actions involving intimate relationships.

After coming to the cities, they work in erotic or semi-erotic environments, such as the nightclubs, karaoke houses, leisure centers and massage parlors that constitute sites for sex business where they utilize their bodies, youth, sexual and social skills to negotiate intimacies with their clients. During the interactions with both clients in a complicatedly sexualized spacetime, they accumulate experience, skills and strength to achieve autonomy and self transformation. For them, the waiting time, casual time, and time in between transactions is not meaningless, but provides opportunities to explore new ways of survival in an environment that is always adverse to them.

In this paper I would like to make three main arguments. Firstly, marriage and intimate relationships have a long-term influence that not only shapes xiaojies' thoughts about leaving their villages and existing relationships, but also motivates them to enter the sex business, as well as encourages them to explore new gender relations. Secondly, their experiences, including as rural wives and as urban xiaojies, and the skills and knowledge they obtain through the latter, open up new possibilities for their future choices concerning intimate relations. Their negotiation of intimacy helps to achieve better deals in their lives. Thirdly, when these women come to the cities, they acquire more life skills and new perspectives/values on gender/sexual relations with an urban reference, and they try to turn these into resources and advantages that may bring economic, social or cultural capital. They do this in a discursive way through everyday acts. Although they may not be able to change substantially their life quality as rural migrants and stigmatized xiaojies, these new skills and perspectives nonetheless raise their self esteem as women, thus bringing emotional satisfaction and carrying symbolic significance. 


\section{METHODOLOGY}

This paper is based on cumulative two years of fieldwork conducted in Guangzhou, Shenzhen, and Dongguan, during periods of 2005, 2006, 2007 and 2008. These cities lie in the center of the Pearl River Delta, South China, adjacent to Hong Kong and Macau and not far from Taiwan - places where the economic "opening-up" of mainland China was first implemented. The data are drawn from the author's ethnographic observations in natural settings such as nightclubs, hair salons, suburban areas, city center streets, the women's homes, on their way to work, etc., and on 23 in-depth interviews with 23 women, aged 18 to 41 (at the time of the interviews), among whom were eleven nightclub girls, six street and/or home-working women, two hair-salon girls, two nightclub mamasans, one call girl and one massage girl. Six of these women were married. Most had migrated to the Pearl River Delta from different parts of China, mostly from neighboring, less-developed provinces such as Hunan $(n=8)$, Sichuan $(n=6)$, Guangxi $(n=5)$, Jiangxi $(n=1)$, and Guizhou $(n=1)$, although one was from suburban Shanghai and one was from north Guangdong. Only two were from small towns considered "urban"; the others were from rural areas.

In the interviews, the following questions were covered: How do some women describe their rural lived experiences and their expectations of urban lives? How do they usually spend their money? How do they manage their lives in the cities as rural-to-urban migrants in the face of the difficulties the cities pose for them? How do they see themselves as urban xiaojies? How do they understand and respond to the strict rules regulating their ages and bodies in the commercial sex sector? How do they describe their marriages and dating experiences? What have they gained or lost in their intimate relationships? What do they think about sex and their bodies? How do they understand their sexual practices vis-à-vis the socially recognized and socially blessed patterns of intimacy, such as those of monogamy and romantic love? How do their love lives influence their life paths and life choices? What are their expectations of life and the future? What do they want from life in the economic, social and cultural context of the Pearl River Delta region?

Some xiaojies were interviewed more than once. All consented to the recordings, which were transcribed verbatim and translated from Mandarin Chinese or Cantonese to English. The names of the women in this study are pseudonyms, or names the women prefer to use.

\section{THE PEARL RIVER DELTA AS A PLACE OF DESIRE}

Most of our informants had finished, or dropped out of, middle school when they were 14 or 15. When they came to the cities their families' annual incomes were mostly under 3000 RMB (approximately US\$ 400 at the time).

The Pearl River Delta, as the forerunner of China's economic opening-up, has become a dreamland of abundance and affluence for such rural people since the 1980s. The 2009 official report on migrant workers (nongmingong 农民工) estimates that there were then over 32 million migrant workers in this region, more than $50 \%$ of whom were women (Duan, Zhang and Lu, 2009). Despite the fact that female migrants have supplied a major labor force driving the region's economic development, they are more marginalized, and suffer more, than their male counterparts, because of sex segregation (Zhang, 2001; Ren and Pan, 2006), unfair "contracts" (Zheng, 2010), harmful working environments, risks to reproductive health, lack of maternity leave, and sexual harassment (Zhang, 2001). Many women earn monthly salaries of 600-700 $\mathrm{RMB}$, and this has remained largely unchanged for over a decade (Cao, 2006). Given inflation 
and increased living costs, their salaries are decreasing. Furthermore, all rural migrants also experience institutional discrimination caused by the complicated household registration system (hukou 户口), which limits the rights of people without local urban hukou.

The household registration system was introduced in 1958, with the intention of controlling population movement between rural and urban areas due to shortages of resources and the ideology of the planned economy. Registration is on a family basis. Every family has a hukou booklet that holds records about each family member, including name, birth date, relationship with other family members, marriage status, spouse (if married), address, employer, etc. There were, and still are, two types of hukou - rural and urban. Residents are categorized separately and are subject to different arrangements regarding health care, retirement, education, work, child care, etc. This has had a great impact on almost every aspect of life.

Free movement was allowed before 1958, but was strictly controlled between 1958 and 1978. A person's hukou thus became extremely important. People were subject to stay in the area where they were born (where their hukou was). Although they could travel, they generally had no access to jobs, public services, health services, education, or even food, in other places - e.g., even if one had enough money to buy food s/he was not able to do so without the hukou of the place where s/he was. To move one's hukou from one place to another was very hard, especially if it was a matter of moving hukou registration from a rural place to a city. If rural people wanted to move to the cities they had to have good reasons to do so. These reasons were limited to the following: to enter universities, for urban employment, and for marriage.

However, the hukou system has gradually come under criticism for severely hindering regional development and violating citizenship rights, so that hukou restrictions are not enforced as strictly as before. This has made it possible for many migrant workers to leave their rural villages and go to cities to seek labor opportunities. Today, such movement is very common. However, migrants have to obtain temporary residence permits to stay in the cities, and are subject to a lot of restrictions of welfare and citizen rights (Fan, 2011).

The recent financial tsunami has made more than 20 million migrant workers jobless (Guo, et al., 2010). The sex industry, in this situation, employs a lot of otherwise unemployed females, as well as those who are disillusioned with factory work but are not able to find better jobs. They have entered the sex business with hopes to live better lives at the interstitial sites of urban life. Many women also enter the industry in order to fulfill various desires, including material, sexual and affective ones. Businessmen and investors from Hong Kong, Taiwan, Macau and abroad provide the demand, and are said to constitute one of the major causes for the proliferation of prostitution since the economic opening-up (Pan, 2000; Ziteng, 2000). However, prostitution has been regarded illegal and thus prohibited by the Chinese legislation ever since the 1980s, and people involved in it are always considered morally wrong and therefore should be detained for their "wrong" behavior (Pan, 2005). The sex industry, however, is developing and thriving, despite constant police raids and crackdowns, albeit in a hidden and scattered manner.

\section{LOVE AND INTIMACY OF FEMALE MIGRANT XIAOJIES}

Current literature on female migrant workers often focuses on their motivations, work, families, future plans, aspirations and marriages (Gaetano and Jacka, 2004; Davin, 2005). Marriage has been an important topic, since many rural-to-urban migrant cases in China directly or indirectly involve marriage. Davin writes that migration, for some women, is a way of "buy[ing] themselves out of a situation in which they are not happy" (e.g., women work to pay 
off divorce costs or child rearing costs after leaving unhappy marital relationships) $(2005$, p.30). Migration, therefore, is considered to "promote female autonomy" (ibid., p.33), especially in a relatively patriarchal rural environment. Beynon (2004), Tan and Short (2004) point out that migration supports exogamy, since many families in rural areas have the tradition of marrying out. Women utilize migration opportunities to seek upward mobility, in terms of financial conditions, social status and stability. These studies also show the dilemmas these women face in marriage and future settlement (Gaetano and Jacka, 2004). It is difficult for migrant women to marry back into the villages they have struggled so much to escape from (Davin, 2005). These authors have analyzed both the agency and the confusions of migrant women, and their analyses reflect the interactions between individuals and their social conditions. It is important and helpful to see how women's individual lives and decisions are situated in broader social and economic conditions.

For xiaojies who not only bear the stigma of migrants but also the prostitution stigma, the situation is more complicated. There is little literature on xiaojies' intimate relations and love lives in local academic studies, which often depict the women as immoral or simply as a subject of public health researches (see Zhang, 2004; Zhang and Han, 2009). They are seldom seen as ordinary women who have passion, love and tender feelings. Pan proposed an excellent starting point for us to look into their lives as everyday women (Pan et al., 2005a, p.95-106). His efforts need to be furthered by analysis based on empirical studies. Zheng's (2008) research shows that bar hostesses in Dalian, north China, were caught in the dilemma between commoditized romance and true romantic love. Their status, on the one hand, enables them to attach a price for each body part and transaction that they consider purely commercial, encouraging them to refuse men's disguised sexual oppression against women; but, on the other, hinders them from seeking ideal love in the cities. As Zheng has written, "romance is a luxury to rural migrant women" (ibid., p.472), given their social positions and resources in relation to those of urban women and non-prostitute women. Individual agency and social constraints are always interplaying with each other in prostitute women's lives, showing both agency and passiveness/victimization (Cheng, 2010). There are increasing voices advocating that these women be seen as persons first of all, rather than being seen either as sexual victims or as sex workers, and that the whole issue be looked at from the perspective of these women's actual lived experiences (Kong, 2006), including their motives, hopes and aspirations, which are the sources and essence of human agency (Cheng, 2010).

The author builds upon these studies to emphasize female desires, and especially the sexual and erotic desires, produced through, as well as stimulating, their everyday life micro-struggles. These desires may not be explicit, clearly expressed or spoken, or in the form of some future plans, and may not be able to bring significant change or substantial improvement in their lives; yet they have emotional and aesthetic significance. In this article the author explores how these women utilize the small moments and objects in their everyday lives in order to create more controllable and satisfactory life spaces, and holds that erotic or sexual subjectivity is important in shaping women's self-awareness and self-images. Through their narratives on marriage, love life, sex and sexual fantasies, we can see more clearly how their selves are being constructed.

\section{MIGRATION: AN ATTEMPT TO BECOME SEXUAL, OPEN AND URBAN}

Beginning in the 1980s, there was an emphasis in China on marital relationships that were emotionally fulfilling between husband and wife. This was quite distinct from the emphasis 
during the Socialist era, as well as from previous emphasis on family relationships that emphasized the relationship between parent and child rather than between husband and wife. This sharp change is documented quite clearly in Xu Xiaohe's study (1998, p.188), which compares Chinese traditional marital relationships with those in the United States. He points out that traditional Chinese marriage was not built on affection, passion, romance, mutual support and sexual gratification, as was marriage in the West, but was solely for the production of male heirs and family unit protection. For a very long time, Chinese marriages were a kind of economic partnership, and the emotional bond almost did not exist (ibid.). The transition from arranged marriage to free choice in marriage emerged in the 1920s following the May Fourth Movement, which indicated a dramatic change in this tradition. Emotional needs are taken as more important elements now in intimate relationships. With the founding of New China and its gradual economic development, the Socialist state made efforts to promote conjugal intimacy based on affective ties to reduce the strong patrilineal kinship-based family bonds and to create citizen-subjects who normalize and govern themselves (Friedman, 2005). State power thus works within and through the citizens. This deliberate effort can be illustrated most clearly in the case of bringing Eastern China's Hui' an women (惠安女) ${ }^{1}$, for whom strong “kin networks, same-sex peers, and village communities guided marital decision making and expectations for proper female behavior" (ibid., p.313), to practice a "liberated" form of marriage. This was facilitated by the interplaying forces of economic development, which bring out individual desires for a new kind of conjugal intimacy, and the ever-stronger state control over population growth (ibid.). A new rise in the divorce rate in China has been revealed, which constitutes a sharp contrast to the virtually zero divorce rate in the 1970s (Huang, 2005); and this relates to the changing cultural norms, the loosening social control on marriage, enhanced education/employment opportunities, increasing individualism, the rise of romantic love, etc.

In the post-reform era, popular culture and mass media constitute a force to influence marriage/intimate relations in two different ways - as based on romantic love, and as based on commercial exchange. Women are constantly balancing themselves between these considerations when they seek their ideal love (Farrer, 2002). Under China's fast developing market economy, economic logic begins to overwrite passion and romance in the forming of any intimate relations (Farrer, 2002; Yan, 2003; Zheng, 2008). Marriage is again related to its non-affective aspects that can create social and economic capital for women to live better. This overarching logic opens up a new opportunity for women to explore alternative ways of intimacy and sexuality outside marriage.

The literature mentioned has provided us with a platform to understand the marital relationships of the rural women who have developed new expectations towards marriage and intimacy and therefore are not be content with what their rural husbands can offer. Some of them venture to find their new lives in the city by becoming xiaojies. Situated at a particular moment of post-socialism in China, these women' ideas and changing expectations towards love, marriage and family constitute a useful lens for understanding Chinese culture, thoughts, values and ways of life, providing as they do a glimpse into the complex interconnections between political, cultural, economic and interpersonal realms of experience.

Amongst the 23 informants, 6 married before they migrated to the city and became xiaojies. For these married women, marriage seems to be a thing to escape from, to be confused about, to struggle for, and perhaps to discard entirely.

The sweetness of marriage may disappear soon when women have to face the brutal reality of rural poverty, child rearing, unsatisfactory marital relation and in-law family relations. Zhenjie, 
who is 41 years old and from rural Hunan, has an "indifferent" and "greedy" husband and in-law family that "only recognizes money". They were "unable to make family any better", and so she and her husband remained very poor and even could not pay their electricity bill of just a few RMB yuan. She thought men should be the bread-winners, but the reality put her to rethink what women could do at a time when men were no longer the main supporters of their families. She left the village at the age of 26 and came to the Pearl River Delta to be a xiaojie. Before she migrated she already had a very clear purpose - she not only wanted to earn more money during her urban stay, but also wanted to know what she could get in the way of love and sexuality. With this in mind she quickly adapted to urban life and overcame difficulties. Her professional skills and social networks built over 15 years' working in the sex business brought her reputation across the region, as well as money and an urban lifestyle. She does not want a divorce because she thinks it is unnecessary, but she lightens her role as a wife and family bread-winner. She started to "enjoy life" by drinking, smoking, betting on horse races and going to nightclubs. From time to time, she buys sex from young male prostitutes and enjoys their "new sexual tricks".

Ya is also from Hunan. She used to a primary school teacher in her hometown. She had a very peaceful life with her husband and a 7-year-old son. Her husband is an "honest, plain but very boring" person. She did not like him much, but her parents thought he was a good choice for a marriage. When life became too dull, she could not help thinking about the life outside the small town she lived in. Her husband is a cadre in a small local government office. He does not know much about the outside world and has no interest in knowing. Ya complained that:

He is having a life that never changes. I felt good at the beginning, thinking that he is very simple and easy to deal with. But I gradually found it too boring, because he doesn't want any changes - even a re-arrangement of our furniture will make him uneasy. I thought it was ridiculous, but things like this happened again and again. He did not have any enthusiasm and only wanted to remain as he was (Ya, 2006).

They quarreled over this many times, and the centre of the problem was the temptation to go out and have a look. Ya was eager to taste a different life and work in a big city, but her husband blamed her for "drifting and irresponsibility". She did not want to take too much time looking after her son and being occupied with household chores, but her husband thought that she should take this responsibility as a mother and wife. Ya felt confused about whether she should leave her family and go to the cities, but finally she made up her mind because she could not stand her husband's "static lifestyle that has no excitement at all". She wanted to try some new lifestyle and explore new possibilities in the cities while she was still young. She went to Shenzhen and there she began to take heroin. Soon she became a xiaojie, soliciting on the streets.

Ya is 40 years old, but she looks a bit younger than her age suggests. She attributes this to her dating a 20-year-old man. She has been living with him for quite a while, and her neighbor Hong joked that they are like a “young couple" (xiao fuqi 小夫妻). She got to know this man through drug taking, and experienced a dramatically different life after dating him. The young man is "cute" and the way he treats her is different from that of her husband. It makes her feel that she has just fallen in love. Ya finds it hard to live without him, although they quarrel all the time over money and drugs. She has to solicit on the streets to earn just enough to pay for the drugs for both of them. She does not like this, since it is "tiring", but the young man depends solely on her 
for money. She told me that she has deep mood swings because, on the one hand, she thinks that she should not be so willful as to leave her son, but, on the other, she reckons that marriage is not right for her. She enjoys the free life in the city but at the same time feels regret at being so "playful". She likes her boyfriend but simultaneously knows he is addicted and lazy. Ya could not resist the temptation to live with him, play with him and take drugs with him because "it's fun, and it makes [her] feel younger, as if [she is] a teenage girl".

She was not sure about whether marriage was good for her since she "would not take things too seriously". She said,

I want to remain like this until one day I can think out a better way to organize my own life. Sometimes I feel confused but I don't want to think too much. Anyway Shenzhen is a good place and it's fun. No one knows me here. I can do whatever I want. Sometimes I almost forget that I am married. Life is like this, it passes without your notice. I don't know what I want but I just want to be free (Ya, 2006).

So she stays in Shenzhen year after year, and does not have any plans so far to return home. Being together with her young boyfriend in a way fulfills her dream of being young, free and having a new lifestyle.

Zhengjie's and Ya's stories illustrate women's expectations of marriage in a traditional Chinese patriarchal culture and their breaking away in search of their own happiness when this tradition becomes oppressive. Their later experience in the cities shows their desire to be sexually attractive, young and modern, and to have sexual experiments and exploration. Their experiences of being xiaojies, who suffer stigmatization and prejudice, in some way gives them insight and power to negotiate gender relations, family roles and sexualities both at home and in the Pearl River Delta.

Contrary to the portrayal of such women as exploited and poor in the literature (Farley, 2006; Wharton, 2010), some women have gained a sense of security from their experience in the sex business. Wen, a 25 year-old woman from Sichuan (southwest China), is working in a classy nightclub at an international hotel in the central business district in Guangzhou. She shares an expensive apartment with three other xiaojies, in a nearby residential block. The district they are working and living in is famous for its commercialization, classy lifestyle and high prices.

She comments on Sichuan men as "not reliable at all", in that "they are so used to being the number one at home" and thus "show no respect to their wives". She thinks that Guangzhou men are more polite, cultured, caring and female-friendly. This is part of the reason she came, keeping open to any opportunities and thinking it was good to be able to have more comparisons and choices.

More importantly, she did not feel "secure" in her marriage. Wen thinks that her decision to migrate and become a xiaojie had a lot to do with her husband's "childlike" lifestyle, which was quite "bad for the family and the future". She complains that he is a spoiled person:

He does nothing at all at home. He's the youngest son and loves drinking. I hate him drinking. Whenever he drinks, I have to look to his needs unconditionally; otherwise he will quarrel with me... A man who is over 30 and has no job, and still has to depend on others...you tell me, how can I believe in him? ... We don't have any savings. Now we don't have a child. What if someday we've got a child? 
We will have to spend money, say, for education for the child. That costs a lot! ...

So I came out here to earn money just in case... (Wen, 2006).

Wen worries about her future, since her husband cannot provide the kind of security that she wants - a regular income and long-term planning to guarantee a stable life. Although her husband has asked her to come home from time to time, and Wen herself sometimes gets very touched by his words, she seems to have made up her mind not to return. Unlike Zhenjie, who is much older and has perhaps arrived at the "seven-year itch" period in her marriage, she is still in the "honeymoon" period. It may be easier for Zhenjie to decide to stay in the city than for her. However, she seems to have a strong desire in her heart to speak out. When I asked her what she wants the most in her life, she pondered for a while and said, "sense of self security (ziwo anquangan 自我安全感)". She said that, for her, this means not only financial security, but also a sense of independence and self assurance over the long run.

Other stories illustrate different situations. For instance, some women said they left home and family for the cities not because of bad marriage experience, but because of their own desire to fulfill sexual needs, to explore new forms of intimacy, or to try a new way of life. They imagine such behavior and lifestyles, such as those of having several boyfriends and lovers, having multiple relations, etc., as connotations of being modern, open and urban. The marital relationship is like a prism through which they see more clearly how gender/sexual relationships work and what they really want (or do not want).

\section{WORKING AS XIAOJIES: SEX AND THE CITY}

In the highly developed sex market of the Pearl River Delta, xiaojies work in increasingly complicated physical environments in which drinking, smoking, various entertainment and performance activities and frequent drug use are all involved. Many sex businesses, especially indoor entertainment sites such as nightclubs, hair salons, massage parlors and leisure centers, have very strict requirements concerning the women's age, body shape and height, as there is a large supply of candidates, and fierce competition. Xiaojies can easily be squeezed out. Even if they manage to get jobs in such places, they are subject to the clients' picky gaze, and constantly find themselves exposed to negative criticisms such as "you are too fat/ugly/thin/short/ old/corny/dark/boring/tasteless in clothes", etc. They cannot earn money simply by providing direct sexual services, but must engage in emotional work and entertainment for customers (Sanders, 2004; Kong, 2006; Bernstein, 2007a,b).

Bernstein's concept of "bounded authenticity" describes the diverse services and experiences of sex workers in the new sex market, which is marked by new communication technologies what the women sell is increasingly an integration of physical work and emotional work $(2007 \mathrm{a}, \mathrm{b})$. Bernstein found that the women manufacture, and deliver to their clients, a sense of real pleasure and desire, making them feel good and even loved in the transactions, but with the clear boundary that it is only temporary. Bounded authenticity is usually a process of "meditation", like "magic arts", that yields true feelings and produces a single self (2007b, p.485-486). But this "bounded authenticity" is usually what is experienced by middle class sex workers, whom Bernstein discusses vis-à-vis working class girls who are involved in "surface acting" (Bernstein, 2007b) skills that tend to produce multiple and divided selves.

Many scholars have cast their eyes on the strategies and skills of prostitute women and argue that they consciously, and sometimes wisely, use them to control their situations, to make sense 
of their own existence and to maintain dignity and autonomy (Dudash, 1997; Day, 1999; Kong, 2006). For example, flirting becomes "strategic", and a kind of expenditure of emotional labor, for exotic dancers (Deshotels and Forsyth, 2006); humor is a strategy for social and psychological distancing (Sanders, 2004); and "acting" and "manufactured identity" are selfprotecting mechanisms, as well as aesthetic and emotional work, involved in female sex work (Sanders, 2005).

However, these studies have been carried out in legal and social environments that are different from those of China, and the women are generally considered as strategic and professional sex workers that have good identity-shifting skills and defense mechanism (Chapkis, 1997). Zheng has categorized the analytical tool used in them as psychological, unlike her own "language of performance" (2007, p.109), and states that Chinese prostitute women maintain a stable true self even though they may perform different roles for their clients. This "character detachment" may originate from a conscious attempt to reduce the negative feelings involved in the work (ibid.), but I think it is rather difficult to identify.

I replace the concept of "identity" or "self" with that of "desire", in order to catch the fluidity and multiplicity of the women's self-identifications, and I highlight the personal desire of the women to become erotic/sexual subjects. Their sexual and affective desires are subtle, yet powerful, motivations for them to migrate, enter the sex business, choose lifestyles, engage in intimate relationships, etc. The sexual desires of these female migrants involved in commercial sex are: to fulfill sexual needs, obtain sexual intimacy and engage in sexual experiments and explorations. The affective desires are: to raise self esteem and to indulge in pleasant feelings and emotional fulfillment.

The women in my study are in no way middle-class. Most of them are second-class citizens (Zheng, 2007) who work in an illegal industry, without legal identity or urban citizenship rights. They do not have many resources generated by formal work experience, economic conditions or social class. However, they can mobilize their resources at hand to "play the game of intimacy" (Cheng, 2007, 2010) just to survive and stand out among the large supply of xiaojies. What they do is rather mundane and trivial, mostly in the sense of "daily tactics" (de Certeau, 1984), but we need to note that this kind of performativity is not just "surface acting" or a set of techniques within clear work-related boundaries - rather, it permeates the women's lives and quietly boosts their self transformations and deliveries.

In my visits to the night entertainment sites, I saw these women's abilities to negotiate intimacies with their clients, and through this process they challenged their existing relationship with clients. However, here I emphasize xiaojies' small talk while waiting for jobs and in trivial daily activities to illustrate how they utilize time on the battlefield to guard their autonomy within the client-xiaojie relationship, and how they give meaning to these seemingly unimportant moments. I see "small" power gathering and growing in these moments.

Appearance and body shape are the most basic issue in the xiaojie-client relationship. Xiaojies' bodies are competing sites where they try their best to be pretty. They usually spend quite a lot of time applying make-up and choosing clothes at home before they leave for work, and during work they frequent the toilet to check whether they still look good. Impression management is essential in their lives. I went to a nightclub in Guangzhou with Wen and Nana one night and sat in the waiting lounge observing what they do there and what they say. There were around 60 girls coming in and out, between their "business hours".

- My blush was smudged by a client just now. He kissed me in the face. 
- You shouldn't wear this skirt, it's too long.

- Look at her, she's tall, but not good-looking.

- She's a model and our boss likes her.

Things like this are what I heard the most that night. I constantly saw the women checking themselves in the mirror. The girls shared with me their "tricks" for appearing sexual. It is actually not important whether one has good-looking breasts or not. The key is to wear a wonderbra to make them look big. In addition, one has to wear very high-heeled shoes and stretch one's body as much as one can so as to look taller and have a nicer body shape. Sometimes the girls will "redirect" clients' hands from their hips or thighs to their breasts because the wonder-bra is "thick and fake" (for this reason it is also a "protection").

Language becomes a useful defense and a re-production mechanism through which xiaojies can modify existing relations between themselves and clients. Gossip about is always the most popular. In such small talk, past events can be re-constructed; memories can be modified; power relations can be altered or even reversed, at least in one's imagination. In these ways, the personal space of the xiaojies is always under construction within their tactical manipulation of space and time.

When with clients, xiaojies take control of when and how much to drink, and may call a stop to any on-going activities and hide in the en-suite toilet to avoid drinking too much, and to have a short break. Usually their drinking will not last long since xiaojies always have good tricks to direct clients' interest to other things like singing, dancing or just caressing; yet they have good "selling" skills to increase alcohol consumption and so earn more through commission, while using excuses to quit drinking and return to the lounge for a break.

Ah Juan once sighed that she loathes the moment where she is gazed at by male clients as they pick up girls like picking up toys, sometimes with rude remarks about their physical appearance. Backstage, however, the girls can counter-strike in speech and imagination. They judge clients' appearance, language, wealth, drinking ability, friendliness, etc., using their own standards. They also talk about clients' sexual skills, and say who is most sexually attractive, who was bad in bed, who would be most suitable to live with and who is a bastard. Sometimes they grasp the short intervals between jobs to discuss how to deal with a particular man, who may be either very disliked or fancied by them. Then they adjust their tactics toward them when they go out again.

Thus they use these interim periods as chances to share experience, explore tricks, or laugh over unhappy incidents, thereby somehow reducing negative feelings, sorting out what to do next, and gaining support from their peers. The moment they step backstage they are different - they "become" by giving new meanings to what they would do or have done, thus taking up these inbetween moments to empower themselves.

Such small occasions, in a Deleuzian sense, are interstitial times full of opportunity to become (Deleuze, 2001). They involve dynamic activity where women express their self love and esteem. They take their direct and intimate interactions with men as a way to comprehend gender and sexual relationships. From their work experience they develop new ways to understand man-woman relationships, and new ways to engage in them - "keep some distance", "position yourself at the right place", "never try to love men too much", "be independent financially", etc.

The variety of clients helps broaden their personal vision, which they utilize as capital and resource for future personal development. Some of them even think working as xiaojie can help 
screen out undesirable men types whom they will not consider for their future lives. Take Lanzi as an example. She got to know a university professor in the massage parlor. She always wanted to go to evening school and so thought it was a good chance. She provided very good massage and free hours to the professor in order to give him a good impression, and she finally succeeded. The professor thinks she is pretty, honest and hard working, and has recommended her to an evening school course. She said she benefited a lot from that.

\section{FUTURE ASPIRATIONS: TO LIVE WITH OR WITHOUT MEN?}

The women's experiences as xiaojies tell them that the institution of marriage may not be the best choice, and that it is only one option among others that may help them achieve what they want. When marriage does not work well, they will consider other options which may have higher "returns", be they financial, emotional or psychological.

There were 17 unmarried xiaojies in my research. Three of them preferred to be single. Thirteen were not sure about whether they wanted to get married or not. Another one wanted to get married, but was careful about choosing the "right one" from her multiple relationships.

Haibin is 26, from rural Shanghai. She is single and lives in an expensive rented apartment in downtown Guangzhou on her own. She goes to a gym every other day, where she not only gets exercise but also meets other women, who are usually single white-collar ladies. This gets her in touch with a cosmopolitan lifestyle. She makes nutritious Cantonese soup to take good care of herself and buys a lot of fashion magazines to read. She told me that her personal space had been broadened, since she has enough time to explore the world around her. She enjoys this kind of single life very much and considers marriage as a last resort. She claims that she will not get married until the day that she feels so miserable that she cannot live on by herself anymore. Marriage to her is only a means to "get money from another person so that you can survive", and should only happens when one has no other way out. She said,

Marriage is something out of my plan. Being a xiaojie helps me to see more clearly about men. This is one thing. Another thing is, I enjoy my current life very much. I feel good about myself and I don't want to bother... Being able to support myself means much more than having a boyfriend and marriage, and I don't think it'll be good having a person around to drag your legs (tuo houtui 拖 后腿 - to hinder one's development). (Haibin, 2006)

The majority of the women interviewed are not as determined as the "no-marriage" people are, but are still eager to find life-long companions who are honest and loving. However, their jobs as xiaojies simultaneously encourage and discourage their pursuit of marriage. They need dependable men who really care about them to reduce their unhappy and lonely feelings but are very skeptical about long-term relationships due to the insights of the job.

YY gave me a lot of pros and cons about marriage when we chatted in her nightclub in Shenzhen. Being loved, cared about and financially supported are the top three things she puts on the "pro" list, while on the "con" list, she includes "being confined, being bored, and losing personal space". This 26-year-old woman has a hierarchy of intimate relationship in her mind. She puts "communication with the heart" at the top of the hierarchy and says that such spiritual communication is the best thing between two persons of opposite sexes. Her dream marriage is one between two people who have such communication. Sexual relationship is in a low position 
in this hierarchy and is regarded as "merely sex".

She puts the relationship between herself and her current boyfriend in the middle. When she faces her boyfriend she can feel affection. However, their relationship is not good enough to convince her to marry. She believes that there are still good men available and that one day she may be able to marry well, but she "just hasn't met the one yet". She admits that it is very difficult to find a man to whom she can "give [her] heart", and so marriage seems to be far away. However, sometimes she thinks that marriage is a "tomb of love", just as "what has been said in the novels". Her experience as a xiaojie tells her that she needs to be very alert in dealing with men, otherwise she may be hurt emotionally or physically.

Through these various marital, extra-marital and intimate practices, the women have developed new understandings of gender relations and have created new sexual scripts for themselves and other stigmatized migrant women. The "playful" lives of those who are married show that wives can also enjoy multiple relationships and that marriage need not be the end of intimacy. The "good woman" image is thus subverted.

As erotic/sexual subjects, the xiaojies in my study resist the existing gender/sexual stereotypes that women should marry early, be subdued and faithful wives, care for their children, be passive in sex, be monogamous, etc. A playful woman can do whatever she wants for pleasure and enjoyment. Since she is "playful and loose", she can show herself proud of her sexual skills without concern that she may be regarded as promiscuous. Xiaojies have gained more knowledge about love and intimacy, which helps to build up their experience and confidence. They realize that marriage is not necessarily the beginning of a good life, and is not their ultimate aim or only choice, and perhaps not a good choice at all. Their sexual values are thus changed and opened up, making them more aware of what a woman can do with her own body and sexuality.

\section{CLOSING REMARKS}

Intimacy means different things to different people, yet to the women I interviewed, it is a platform on which to transform themselves. In different stages of their lives, they have built up different understandings of intimacy, which has made it an on-going project of the self (Foucault, 1988). This paper illustrates xiaojies' expectations and aspirations of love and marriage through the lens of China's rural-urban migration and rapid economic development. It reveals that in intimate relationships, such as marriage, xiaojie-client relationship, extra-marital relations and cohabitation, these women constantly negotiate their roles and revise existing gender relations by accumulating small discursive powers. They are constantly searching for what they want and express their desires through seemingly deviant thoughts and remarks. This is the way they evolve and become stronger.

Our literature seems largely to ignore the importance of intimate relationships as an ongoing effect in the pre-migration, migration, and post-migration processes, and the impact they have on the women who finally take up xiaojie as their job. Not all xiaojies migrate for money economic drive is, of course, a major factor in leading them to leave their rural villages, but the narratives of my informants brings out other desires - to escape unhappy relations and to be modern women; to be young, sexy, urban and virginal; and to leave their rural villages and their original familial and marital bonds and migrate to the cities for greater personal opportunities and a better living environment.

The migrant women/xiaojies in the Pearl River Delta desire to be erotic/sexual subjects who are sexy, youthful, open, autonomous, urban and modern. This desire has an on-going influence 
on their thoughts and behaviors, including migration, entering the sex business - they challenge marriage as the only normative way of intimacy for women and experiment with different practices of intimacy. They accumulate resources such as sex knowledge, skills, values, interpersonal relationships, etc. from their intimate relations, and employ unconventional sexual practices to transform themselves into the kind of women that they want to be. As xiaojies, their sexual/semi-sexual jobs thus become channels for them to realize their desires.

Desire is a useful concept in understanding women's lived experiences. Although the possibility of becoming legal urbanites is slim, the xiaojies think it worthwhile to see the urban world and experience its life even in the most superficial way. Taking on urban appearances, developing personal networks, living an urban lifestyle, engaging in alternative intimate relations, etc., reifies their urban dreams in material and affective forms. To other people, the "small" things that the women get by leaving their hometowns and families and becoming involved in the sex industry may seem irrational, and economically unsound, and may cause alienated feelings and do harm to them. They will certainly not give them the legal and social status that they need, and thus are not seen as worthy of pursuit. However, they have symbolic significance to xiaojies when social and legal recognition is perhaps the hardest to obtain. This is their own unique way to participate in China's fast economic development and modernization. Through them they achieve a kind of symbolic recognition of themselves as "urban" - this is a kind of vanity and self esteem, and a form of self expression that may bring positive and pleasant feelings. It is through these superficial practices that their subjectivity is constituted, and this is something that we should not neglect or misunderstand.

Note: Hui'an women are renowned for their unusual costumes and customs of marriage. Their parents would arrange their marriages at an early age. After marriage, they spent most of their time, even their entire life in their maiden homes. They couldn't sleep with their husbands and have to stand by the bed in the first evening of marriage, and after three days they had to return to their maiden homes. They could not meet their husbands again until New Year's Eve, but they still had to go back to their maiden homes the next day. As such, they could only stay with their husbands for a few days throughout the year until they give birth to a child. Otherwise, they had to stay with their parents in their maiden homes for their entire lives.

Acknowledgement: I am indebted to all the interviewees whom I have come to know during this study. They shared with me their happiness and sadness, fun stories and witty tricks, and these made the completion of this research possible. In preparing the manuscript I have been helped by Dr. Robert G. Tian and Dr. John F. Thorne, who have not only read through the drafts and helped with editing matters, but also given me detailed and constructive feedback. Special thanks go to Professor Zhou Daming and Professor Cai He who offered generous help and advice during the publication of this manuscript.

\section{REFERENCES}

Agustin, L. M. (2005). The Cultural Study of Commercial Sex. Sexualities, 8 (5): 618-631.

Barry, K. (1995). The Prostitution of Sexuality. New York: New York University Press.

Bernstein, E. (2007a). Temporarily Yours: Intimacy, Authenticity, and the Commerce of Sex. 
Chicago: The University of Chicago Press.

Bernstein, E. (2007b). Sex Work for the Middle Classes. Sexualities, 10 (4): 473-489.

Beynon, L. (2004) Dilemmas of the Heart: Rural Working Women and Their Hopes. In: Gaetano, A. \& Jacka, T., (Eds.) On the Move: Women and Rural-to-Urban Migration in Contemporary China. New York: Columbia University Press. Pp. 131-150.

Califia, P. (1994). Public Sex: the culture of radical sex. Pittsburgh: Cleis Press.

Cao Y. (2006). The average monthly income of the migrant workers in the Pearl River Delta has increased by only 68 yuan in 12 years. Retrieved in Oct. 2011 from http://news.163.com/06/0419/11/2F2NCVUT0001124J.html

Chapkis, W. (1997). Live Sex Acts. New York: Routledge.

Chapman, M. (1996). Social Anthropology, Business Studies, and Cultural Issues. International Studies of Management \& Organization, 26 (4): 3-29.

Cheng, S. L. (2007). Romancing the club: Love dynamics between Filipina entertainers and GIs in U.S. military camp towns in South Korea. In: Padilla, M. B. et al. Love and Globalization: Transformation of intimacy in the contemporary world. Nashville, Tenn.: Vanderbilt University Press. Pp. 226-251.

Cheng, S. L. (2010). On the Move for Love: Migrant Entertainers and the US Military in South Korea. Philadelphia: University of Pennsylvania Press.

Davin, D. (2005). Women and Migration in Contemporary China. China Report, 41 (1): 29-38.

Day, S. (1999). Hustling: Individual Among London Prostitutes. In: Day, S., E. Papataxiarchis and Stewart, M., (Eds.) Lilies of the Field. Oxford: Westview Press. Pp. 137-157.

De Certeau, M. (Trans.) Rendall, S. F. (1984). The practice of everyday life. Berkeley: University of California Press.

Deleuze, G. (Trans.) Boyman, A. (2001). Pure Immanence: Essays on a Life. New York: Zone Books.

Deshotels, T. \& Forsyth, C. J. (2006). Strategic Flirting and the Emotional Tab of Exotic Dancing. Deviant Behavior, 27 (2): 223-241.

Duan, C. R., F. Zhang, \& Lu, X .H. (2009). State of Migrant Women Population in China. Collection of Women's Studies, 4: 13-20.

Dudash, T. (1997). Peepshow Feminism. In: Nagle, J., (Ed.) Whores and Other Feminists. London, New York: Routledge. Pp. 98-118. 
Fan, S. D. (2011). The Generality and Particularity of Labor Migration in China. South China Population, 26 (3): 35-46.

Farley, M. (2006). Prostitution, Trafficking, and Cultural Amnesia: What We Must Not Know in Order to Keep the Business of Sexual Exploitation Running Smoothly. Yale Journal of Law \& Feminism, 18: 109-143.

Farrer, J. (2002). Youth Sex Culture and Market Reform in Shanghai. Chicago: Univ. of Chicago Press.

Foucault, M. (1988). Technologies of the Self. In: Martin, L. H., H. Gutman and Hutton, P. H., (Eds.) Technologies of the Self: A Seminar with Michel Foucault. Amherst: The University of Massachusetts Press. Pp. 16-49.

Friedman, S. L. (2005). The intimacy of state power: Marriage, liberation, and Socialist subjects in southeastern China. American Ethnologist, 32 (2): 312-327.

Gaetano, A. M., \& Jacka, T. (Eds.), (2004). On the Move: Women and Rural-to-Urban Migration in Contemporary China. New York: Columbia University Press.

Guo, W. Q. et al. (2010). The income and expenditure of rural migrant workers in the financial crisis. Paper presented on the Conference of "Migrant Workers in the Financial Crisis" held on Jan 15, 2010, at the Sun Yat-sen University, Guangzhou, China.

Huang, W. J. (2005). An Asian Perspective on Relationship and Marriage Education. Family Process, 44 (2): 161-173.

Jordan, A. T. (2010). The Importance of Business Anthropology: Its Unique Contribution. International Journal of Business Anthropology, 1 (1): 7-17.

Kong, T. S. K. (2006). What It Feels Like for a Whore: The Body Politics of Women Performing Erotic Labour in Hong Kong. Gender, Work and Organization, 13 (5): 409-434.

Pan, S. M. (2000). Subsistence and Experience. Beijing: China Social Science Publishing House.

Pan, S. M. et al. (2005). Situation and Inspiration: Study on three red-light districts in Southwest China. Kao Hsiong: Universal Press.

Pateman, C. (1988). The Sexual Contract. Cambridge: Polity Press.

Tan, L., \& Short, S. (2004). Living as Double Outsiders: Migrant Women's Experiences of Marriage in a County-Level City. In: Gaetano, A. \& Jacka, T., (Eds.) On the Move: Women and Rural-to-Urban Migration in Contemporary China. New York: Columbia University Press. Pp. 151-176. 
Wharton, R. L. (2010). A New Paradigm for Human Trafficking: Shifting the Focus from Prostitution to Exploitation in the Trafficking Victims Protection Act. William \& Mary Journal of Women \& the Law, 16 (3): 753-780.

Ren, Y. \& Pan, Y. (2006). The Spatial Politics of Transnational Labor Process: Dormitory labor regime in the age of globalization. Sociological Research, 4: 21-33.

Sanders, T. (2004). Controllable Laughter: Managing Sex Work through Humour. Sociology, 38 (2): 273-291.

Xu, X. H. (1998). Convergence or Divergence: The transformation of marriage relationships of urban America and urban China. Journal of Asian and African Studies, 33 (2): 181-202.

Yan, Y. X. (2003). Private Life under Socialism: Love, Intimacy, and Family Change in a Chinese Village, 1949-1999, Stanford, CA: Stanford Univ. Press.

Zhang, H. Y. \& Han, Y. H. (2009). Discussions on a hotspot in the prevention and control of AIDS - Refuting the legalization of prostitution from bio-ethical perspectives. Journal of Kunming University of Science and Technology (Social Sciences), 2: 76-84.

Zhang, Y. (2001). Migrant Women Workers and the Emerging Civil Society in China.The Asia Foundation, URL: http://asiafoundation.org/pdf/ZhangYe.BSR.pdf

Zhang, Y. H. (2004). The Causes of the Formation, Essence and Harm of the Current Hedonism. Journal of Shanxi Normal University (Social Science Edition), 1: 18-23.

Zheng, G. H. (2010). Towards A Sociological Understanding of Employee's Mental Health. Sociological Research, 6: 201-222.

Zheng, T. T. (2007). Performing Media-Constructed Images for First-Class Citizenship: Political Struggles of Rural Migrant Hostesses in Dalian. Critical Asian Studies, 39 (1): 89-120.

Zheng, T. T. (2008). Commodifying Romance and Searching for Love Rural Migrant Bar Hostesses' Moral Vision in Post-Mao Dalian. Modern China, 34 (4): 442-476.

Ziteng. (2000). Research Report on Mainland Chinese Sex Workers: Hong Kong, Macau and Town B in the Pearl River Delta. Ziteng. Retrieved in Oct. 2011 from: http://www.ziteng.org.hk 